\title{
Why do general dental practition- ers become involved in clinical teaching? A pilot study exploring the views of part-time practitioner teachers, King's College London
}

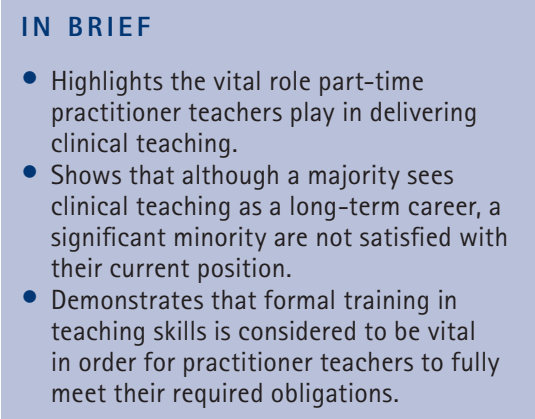

IN BRIEF

Highlights the vital role part-time practitioner teachers play in delivering clinical teaching.

Shows that although a majority sees clinical teaching as a long-term career, a significant minority are not satisfied with their current position.

Demonstrates that formal training in in order for practitioner teachers to fully meet their required obligations.

\author{
B. R. Davies, ${ }^{* 1}$ A. N. Leung ${ }^{1}$ and S. M. Dunne ${ }^{2}$
}

Introduction Dental schools in the United Kingdom are becoming increasingly reliant on the services of part-time teachers to deliver the clinical educational component of the dental course. Their background is predominantly from general dental practice but the opportunities to progress in the system are limited. The aim of this study was to ascertain the views and perceptions of such teachers at a dental school. Materials and methods An anonymous, non-incentivised online survey was used to obtain both qualitative and quantitative views of the part timers. Results The department has $n=40$ part-time teachers and there was a response rate of 78\%. Overall $73 \%$ were satisfied with their current teaching position, whereas the remaining $27 \%$ of teachers were seeking higher rewards both in terms of recognition and status. Conclusions This study demonstrated the need for formal teaching skills and training to be made available to part-time clinical teachers. Allied to this is the requirement for a clearly defined and achievable career pathway.

\section{INTRODUCTION}

UK university medical and dental schools have well established career pathways for full-time academic and clinical staff, ${ }^{1}$ leading ultimately to appointment at either consultant or professorial level.

However, the potential for career progression for the part-time general practitioner who contributes one or two days per week to clinical teaching is limited. In the institution where the authors teach, grades are currently confined to clinical teacher and senior clinical teacher. If the teacher is on a specialist list then the grade senior specialist clinical teacher applies.

In addition, the requirements for promotion from clinical teacher to senior clinical teacher are onerous, including a minimum of three days per week clinical teaching, demonstrable leadership within the undergraduate syllabus and possession

\footnotetext{
The Maurice Wohl Dental Practice Centre, Department of Primary Dental Care, Kings College London Dental Institute, Bessemer Road, Denmark Hill, London, SE5 9RW; ${ }^{2}$ Department of Primary Care/Advanced General Dental Practice, Kings College London Dental Institute, Bessemer Road, Denmark Hill, London, SE5 9RW

${ }^{*}$ Correspondence to: B. R. Davies

Email: brian.r.davies@kcl.ac.uk
}

\section{Refereed Paper}

Accepted 26 February 2013

DOI: 10.1038/sj.bdj.2013.433

${ }^{\circ}$ British Dental Journal 2013; 214: 461-465 of a relevant postgraduate qualification and a teaching qualification.

Dental education in the UK has experienced a period of unprecedented growth over recent years. There have been huge increases seen in the numbers of both undergraduate and postgraduate students ${ }^{2}$ together with an accompanying growth in diversities, ${ }^{3}$ new pedagogic advances, ${ }^{4}$ higher all round expectations and of late, a funding squeeze. ${ }^{5}$

Current dental educators face a bewildering array of complex challenges and issues. The constant drive for personal professional and public accountability is ever set against the growing needs and demands of a sophisticated student body. ${ }^{6}$

Integrated primary patient care drives a plethora of research and development activity, which in turn feeds into the general milieu of dental education. The standard of education is regulated in accordance with the 1984 Dentists Act and the relevant regulations through the guidance published by the General Dental Council (GDC), the current one being Preparing for practice: dental team learning outcomes for registration. ${ }^{7}$

Within this guidance, the GDC, inter alia, places much emphasis on communication skills for the dental team, teamwork and professionalism, and the management of the clinical and working environment for individual patient care.

Primary dental care is perhaps the most significant area of clinical activity in the UK and where the majority of practising dentists are to be found. Committed part-time teachers drawn from this sector form a hugely important resource for any dental school, supporting as they now do the majority of the undergraduate clinical curriculum ${ }^{8}$ and a growing share of responsibilities in the post graduate sector.

\section{AIMS}

This subject area is poorly reported with very little targeted research published. There are many widely held and differing opinions as to why general dental practitioners teach. Some are incorrect, incomplete or based on assumptions and perceptions that have no evidence base. This study attempts to address some of these shortfalls by exploring, through qualitative methodology, issues that affect the practitioner teacher. It is hoped that this work will stimulate a forum for debate and discussion for clinical educators from the rest of the UK and beyond. The authors believe it is timely to look into this important but long neglected 
area in order to better inform practice and to address some of the needs of part-time practitioner teachers.

\section{METHODS AND MATERIALS}

The cohort $(n=40)$ identified from the department's e-mail list were sent an anonymous online questionnaire (via www.surveymonkey.com) that had been developed, piloted and modified. They were invited to express their views as current clinical teachers. A follow-up reminder was provided two weeks later.

The survey was anonymous and designed to elicit both mixed qualitative and quantitative data. The questions are displayed in Table 1.

\section{RESULTS}

The data derived from the questionnaire are presented in Tables 2-5.

The total number of completed electronic questionnaires received was 31 , giving a response rate of $78 \%$.

Information in relation to the post-qualification experience, the length of service and the relative amount of teaching undertaken by the part-time clinical teachers in the department are collated in Table 3.

The two main thematic responses arising from the qualitative questions are collated in Table 5.

The respective quantitative findings for teachers expressing satisfaction or dissatisfaction are collated in Table 6.

The typical qualitative themes identified from teachers expressing overall satisfaction (73\% of the cohort) or dissatisfaction (27\% of the cohort) is collated in Tables 7 and 8.

\section{DISCUSSION}

The use of an electronic questionnaire to gather data for this study offers many advantages. It has enabled an entire cohort of part-time teachers working on different days to be anonymously surveyed with relative ease and convenience. This approach is both cost effective and efficient compared with other more resource intensive methods.

The overall response rate of 78\% is broadly in line with other similar non-incentivised surveys. ${ }^{9}$ However, there may have been a degree of selection bias within the respondent group. It is reasonable to assume that those who were more enthusiastic about

\section{Table 1 The questionnaire used in the survey}

What year did you qualify as a dentist?

How long have you been teaching in the department?

How many sessions do you teach in the department per week? ( 1 day = 2 sessions)

Are you content with your position as a part-time clinical teacher?

Do you see this as a long-term career for you?

Please rank in order of importance why you choose to teach in the department

( 1 = most important, 7 = least important)

Remuneration/Status/Lack of current career direction/Keeping up-to-date/Professional contacts with colleagues/As a vocation/As part of your general career development

Are you positively encouraged to develop your career as a clinical teacher? - please elaborate.

Do you feel it is necessary to acquire formal teaching skills and training in your role?

How should part-time clinical teachers be best rewarded for their input and support to the department? Please elaborate.

Would a viable career pathway encourage you to continue as a part-time clinical teacher? Please elaborate

Table 2 Response rate for the survey

\begin{tabular}{l|l|l} 
Number in cohort & Number of responses received & Response rate \\
\hline 40 & 31 & $78 \%$
\end{tabular}

\section{Table 3 The cohort structure and identification of key teaching attributes}

\begin{tabular}{|l|l|}
\hline Mean number of years of post-qualification clinical experience & 18.5 \\
\hline Mean number of years of teaching experience at the department & 5.8 \\
\hline Mean number of days taught per week at the department & 1.3 \\
\hline Total number of full-time staff equivalent contributed by the part-time clinicians & 10.4 \\
\hline
\end{tabular}

Table 4 Main quantitative findings of the cohort

\begin{tabular}{l|l} 
& $\begin{array}{l}\text { Quantitative } \\
\text { findings (\%) }\end{array}$ \\
\hline Staff in the first year teaching at the department & 23 \\
\hline Staff in the first five years teaching at the department & 61 \\
\hline Staff teaching over 10 years at the department & 23 \\
\hline Staff teaching over 15 years at the department & 3 \\
\hline 'Content with current position as a part-time clinical teacher' & 74 \\
\hline 'Seeing clinical teaching as a long-term career' & 68 \\
\hline Main reasons for teaching in the department: & \\
As a vocation & 35 \\
Career development & 32 \\
Professional contact with colleagues & 26 \\
Lack of current career direction & 16 \\
Remuneration & 6 \\
Status & 3 \\
To keep up-to-date & 3 \\
\hline 'Being positively encouraged to develop a career as a clinical teacher' & 48 \\
\hline 'Feel it is necessary or desirable to acquire formal teaching skills and training in my role' & 97 \\
\hline $\begin{array}{l}\text { Part-time clinical teachers would best be rewarded by: } \\
\text { Further careers opportunities and development }\end{array}$ & 58 \\
Being appreciated \\
Better remuneration \\
Better training opportunities \\
Involvement in research & 29 \\
\hline 'A viable career pathway would encourage me to continue as a part-time clinical teacher' & 26 \\
Yes & 26 \\
No No preference & 6 \\
\hline & 10 \\
\hline & 10 \\
\hline
\end{tabular}




\section{Table 5 Representative responses in respect of identified themes}

\begin{tabular}{|c|c|}
\hline $\begin{array}{l}\text { Thematic characteristics identified by } \\
\text { the qualitative questions }\end{array}$ & $\begin{array}{l}\text { Representative responses in respect of the identified } \\
\text { themes: }\end{array}$ \\
\hline $\begin{array}{l}\text { Whether they are positively encouraged to } \\
\text { develop their careers as clinical teachers } \\
\text { (Two main views have been identified) }\end{array}$ & $\begin{array}{l}\text { Affirmative: 'The head of my unit has been very supportive } \\
\text { going out of his way to make sure I have been given mean- } \\
\text { ingful opportunities to develop my career' } \\
\text { Non-affirmative: '....there does not seem to be any formal } \\
\text { career progression' }\end{array}$ \\
\hline $\begin{array}{l}\text { How clinical teachers should best be } \\
\text { rewarded } \\
\text { (Four main themes have been identified) }\end{array}$ & $\begin{array}{l}\text { Parity with full-timers: 'A viable career pathway alongside } \\
\text { the full-timers and the appropriate title to go with it is } \\
\text { important' } \\
\text { Structure and title: 'A structured pathway with appropriate } \\
\text { designations or grading would help reflect the worth and } \\
\text { status of the individual teacher' } \\
\text { Financial reward: 'Whilst not the main motivation for teach- } \\
\text { ing, financial reward is important, as we leave our private } \\
\text { practice to dedicate the time and travel four hours a day to } \\
\text { teach' } \\
\text { Expect nothing: 'I think this is a privilege to teach at King's } \\
\text { and whoever loves teaching does not expect to be rewarded' }\end{array}$ \\
\hline
\end{tabular}

Table 6 Respective quantitative findings for teachers expressing satisfaction or dissatisfaction

\begin{tabular}{l|l|l}
\hline$(n=30)$ & $\begin{array}{l}\text { Teacher seen as overall } \\
\text { satisfied }\end{array}$ & $\begin{array}{l}\text { Teacher seen as overall } \\
\text { dissatisfied }\end{array}$ \\
\hline Prevalence & $73 \%$ & $27 \%$ \\
\hline Mean post qualification experience & 16.5 years & 20.8 years \\
\hline Average time spent in department & 4.5 years & 7.6 years \\
\hline Average no. of days per week in the department & 1.3 & 1.4 \\
\hline
\end{tabular}

Table 7 Respective findings for higher aspirational teachers seen as dissatisfied overall $\mathbf{n}=\mathbf{8}$ ( $27 \%$ of cohort)

Representative comments reflecting main areas of discontent from the teachers

'Just an acknowledgement of positive input would be good'

'Promotion to higher grades which reflect qualifications, experience and specialist status'

'Status and titles to reflect the levels of responsibility and contributions made to the department'

'With some form of training long term followed by certificates for new teachers and money for senior teachers'

'More support from the full time staff. Reduce the workload by employing more teachers.

Increase remuneration and a more defined career pathway'

'A viable career pathway alongside full timers... PDC would simply not survive without their contributions... a proper title and a viable pathway cost the institution very little'

'Better career development opportunities, at present we can't be absent to attend courses or committees. More chance to become involved in research'.

'...recognition of their work-pay is too poor at a junior level'

their work would be more likely to respond than those who were not.

The design of the questionnaire allowed respondents to answer the questions honestly and in privacy, thereby potentially increasing the validity and reliability of the study.

Although comparatively small in terms of overall numbers, the survey covered an entire cohort of part-time teachers and provides a useful insight into the reasons behind their continuing involvement in clinical teaching as well as their professional aspirations.

Tables 5, 7 and 8 summarise the recurring themes identified throughout this study. They were arrived at by immersing the data and scrutinising the text responses in order to develop collective generalities, thereby confirming the theme. ${ }^{10}$

From this study two principal cohorts of teacher were identified. In the first the majority of the head count belonged to staff with five years or less teaching experience (61\%) with almost a quarter of these (23\%) in their first year of teaching. This is similar to the findings reported by others. ${ }^{11}$ The mean post-graduation experience was 16.5 years in the first group rising to almost 21 years in the second. Both cohorts contained practitioner teachers with advanced training and experience in primary dental care. The amount of time spent in the department was almost identical in each case, being on average a little over one day per week.

Nearly two thirds of the overall group appeared satisfied with their current position with a similar number seeing clinical teaching (part-time) as a long-term career option. However, one significant and striking observation was the virtually unanimous recognition across both groups of the need to acquire formal teaching and training skills ${ }^{12}$ in order to fulfil the role of a present day clinical teacher. ${ }^{13}$

This finding alone has potentially far reaching consequences for those who organise and employ part-time clinical teachers. ${ }^{14}$ It is becoming an inescapable fact that teaching (delivered at a dental school) should conform to a core of knowledge and be within a framework that demonstrates that required professional standards have been met. ${ }^{15}$

This institute currently offers its teaching staff free access to an extended teaching programme, which has enabled increasing numbers of part-time staff to further develop their contextualised skills and understanding of clinical teaching and education, mapped to the UK Professional Standard Framework in accordance with the guidelines from the Higher Education Academy. ${ }^{16}$

Of the $27 \%$ of teachers identified as not satisfied with their position, the numbers were principally (but not exclusively) drawn from those who had spent significant amounts of time in the department (Table 6). On average this cohort had spent $69 \%$ more time in the department as compared with those who stated they were satisfied with their position.

The key issues raised by many of these experienced teachers appear principally to be associated with perceived lack of status, title and career progression. The survey also reflects the fact that the current 
part-time teaching workforce stays with the department on average for 5.8 years, with $25 \%$ of them within the first year of their appointments. This level of dissatisfaction tends to reinforce the case for a coherent career pathway in order to improve quality, retention and job satisfaction for part-time clinical teachers, in line with observations reported by others. ${ }^{17}$ There are also echoes in this study that link to the known economic pressures on healthcare, dental schools and recruitment. ${ }^{18}$ The reliance on part-time clinical staff ${ }^{19}$ and the conflicting demands of research, service, teaching and practice commitments for part-time teachers, ${ }^{20}$ together with perceptions of the student clinical experience ${ }^{21}$ all add further support for the case for more work in this area.

With more graduate entry students found in dentistry, including those from parallel disciplines such as medicine and pharmacology $y^{22}$ it is suggested that their differing outlooks and demands, in part reflecting new fee structures will need to be addressed by an increasingly effective teaching workforce.

An encouraging trend seen in this study was the positive ranking of vocation, career development and professional contact, ahead of such attributes as lack of career direction, remuneration or status. Furthermore, professional contact with colleagues was considered important for a sizeable proportion (26\%) of the survey; perhaps reflecting in part the often isolated nature of general dental practice. Indeed 91\% of dentists on the GDC register according to the Faculty of General Dental Practice are described as general dental practitioners. ${ }^{23}$ An interesting observation reported from the respondents confirmed that on average part-time teachers spend 1.3 days per week in the department and deliver approximately $85 \%$ of the overall clinical teaching received by the students.

Part-time clinical teachers bring with them a wealth of experience, knowledge and expertise from precisely the area in which most dental graduates will practice. Their continuing contribution remains vital for the department to function as a viable teaching entity. A recent advance towards investment in educational development by individual teachers themselves now means there are already practitioner teachers at masters level with others to follow.

Table 8 Respective findings for higher aspirational teachers seen as satisfied overall $\mathbf{n}=\mathbf{2 2}$ (73\% of cohort)

Representative comments reflecting main areas of teaching satisfaction from the teachers

'... am drawn to teaching for so many reasons such as my desire to pass on my experience to students...'

'... enjoy my position as a clinical teacher, especially feeling rewarded when my students give good feedback'

...multiple teachers suggest I should look into a career in teaching and I am given help and support from all staff to develop this aspect should I wish'

'There is definitely lots of help and encouragement from colleagues'

'I have learnt a lot and am keen to pass on my knowledge to up and coming students...

'I think this is a privilege to teach at King's and whoever loves teaching does not expect to be rewarded'

'I can't think of any reward I need beyond the job satisfaction itself'

'...having more time with senior people to help career planning'

'Yes, GCAP (teaching) programme'

'whilst not the main motivation for teaching-financial reward is important'

...not many part timers will want or be able to go beyond senior clinical teacher. However, I would suggest the title of Senior Clinical Teaching Fellow"

'Currently enrolled on the PG CAP course'

...postgraduate training and development is encouraged in the form of courses and education training

'Rewards are not necessary. Annual get together-perhaps funded by department'

'I feel very privileged as rewarded anyway-I personally don't have any further need for reward as I enjoy giving something back'

'I thoroughly loved my time at KCL and wishes to give back as much as possible'

'Remuneration is not usually the prime motivator for clinical teachers. A structured pathway with appropriate e designations or "grading" would help reflect the worth and status of the individual teacher'

'Yes, I really enjoy it'

'Simple appreciation works for me'

'...Dr A and Dr B have harnessed my desire to progress in my career and I will be studying the PGCAP this year'

'Positive reward is not my aim. My reward is imparting my skills to the new generation of dental surgeons and seeing them qualify'

Allied to this there is significant growth in outreach teaching and its attendant need for additional high quality primary care practitioner support. ${ }^{24}$ This picture of increased part-time teaching activity contrasts sharply with the shrinking number of career academics now to be found within dentistry. ${ }^{25}$ To date there are no signs of any current changes to this trend. ${ }^{26}$

\section{CONCLUSION}

Part-time teachers have a very strong influence on the success or otherwise of the modern clinical curriculum. In our view they remain a vital but largely overlooked resource. To quote directly from one respondent:

'The Dental School would simply not survive without their contributions... a proper title and a viable career pathway would cost the institution very little'.

It is clear from our research the majority of part-time teachers do not seek remuneration as their main reward. It is our belief that job satisfaction, career enhancement and, in appropriate cases, a title befitting of status along with a viable career pathway are the likely main drivers. It is not known if other UK dental schools have similar experiences to report and what career structures are in place to encourage and reward teaching excellence and leadership.

These findings challenge the traditional ad hoc approach to clinical teachers that for so long has underpinned the system both in the UK and elsewhere. It is difficult to see how high teaching standards will be maintained when more and more reliance is placed upon part-time teachers, many of whom may have difficulty accessing appropriate teacher training and whose efforts are often insufficiently accredited or recognised.

1. Margerison, C, Morley H. Clinical academic staffing levels in UK medical and dental schools: a report by the Medical Schools Council and the Council of Heads and Deans of Dental Schools. Medical Schools Council, 2007.

2. Martin N, Fairclough, A, Smith M, Ellis L. Clinical educators' views on the quality of undergraduate clinical resorative dentistry in the UK and ROI. Eur Dent Educ 2011; 15: 216-222.

3. Murray J J. Pressures on dental education-a personal view. Br Dent J 2002 192: 433-435.

4. Oakley M, Vieira A R. The endangered clinical teacher scholars: will this eliminate discovery from the dental school environment? J Dent Res 2008; 87: 200-202. 
5. Higher Education Funding Council for England (HEFCE). Guide to funding: how HEFCE allocates its funds. Bristol: HEFCE, 2010.

6. National Student Survey 2011. NSS, 2011

7. General Dental Council. Preparing for practice: dental team outcomes for registration. London: GDC, 2011.

8. Dental Schools Council. Staffing levels of dental clinical academics and dental clinical teachers in the UK dental schools. London: Dental Schools Council, 2009.

9. Asch D, Jedrziewski M, Christakis N. Response rates to mail surveys published in medical journals. J Clin Epidemiol 1997; 50: 1129-1136.

10. Richards L. Handling qualitative data: a practical guide. Sage 2005; 156-162.

11. O'Sullivan E M. The demographic and academic profile of Irish dental school faculty members. J /r Dent Asoc 2009; 55: 296-301.

12. Carrotte P. Educating the educators - do university lecturers require training in educational practice? Br Dent J 1994; 177: 217-220.

13. Sweet J, Wilson J, Pugsley L. Chairside teaching and the perceptions of dental teachers in the UK. Br Dent J 2008; 205: 565-569.
14. Corbet, E, Akinwade, J, Duggal $R$ et al. Staff recruitment, development and global mobility. Eur J Dent Educ 2008; 12: 149-160.

15. The Higher Education Academy. Framework guidance note 3. What are the dimensions? York: HEA, 2012. Online article available at http://www.heacademy.ac.uk/assets/documents/ukpsf/frameworkguidance-3.doc (accessed March 2013).

16. The Higher Education Academy. UK professional standards framework (UKPSF). York: HEA, 2011. Online information available at http://www.heacademy.ac.uk/ukpsf (accessed March 2013).

17. Aggarwal V R, Palmer N O, Nelson P, Ladwa R, Fortune F. Proposed career pathway for clinical academic general dental practitioners. Prim Dent Care 2011; 18: 155-160.

18. Murray J J. Pressures on dental education-a personal view. Br Dent J 2002; 192: 433-435.

19. O'Sullivan E M. The demographic and academic profile of Irish dental school faculty members. J Ir Dent Assoc 2009; 55: 296-301.

20. Martin N, Fairclough A, Smith M, Ellis L. Clinical educators' views on the quality of undergraduate clinical restorative dentistry in the UK and ROI. Eur J Dent Educ 2011; 15: 216-222.

21. Davies B, Leung A, Dunne S. So how do you see our teaching? Some observations received from past and present students at the Maurice Wohl Dental Centre. Eur J Dent Educ 2012; 16: 138-143.

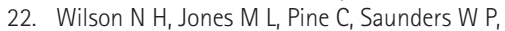
Seymour R A. Looking forward: educating tomorrow's dental team. Eur J Dent Educ 2008; 12: 176-199.

23. Aggarwal V, Palmer N O, Nelson P, Ladwa R, Fortune F. Proposed career pathway for clinical academic general dental practitioners. Prim Dent Care 2011; 18: 155-160.

24. Craddock H L. Outreach teaching - the Leeds experience: reflections after one year. Br Dent J 2008; 204: 319-324.

25. Corbet E, Akinwade J, Duggal R et al. Staff recruitment, development and global mobility. Addis Ababa College of Dental Sciences, Ethiopia. Eur J Dent Educ 2008; 12: 149-160.

26. Kay $E J$, 'O'Brien K D. Academic dentistry - where is everybody? Br Dent J 2006; 200: 73-74 